\title{
Traumatiske ryggmargsskader - forekomst, skademekanismer og forløp
}

Engelsk oversettelse på www.tidsskriftet.no

\begin{abstract}
Sammendrag
Bakgrunn. Hovedformålet med denne artikkelen er å gi en oversikt over demografi, skadenivå, skadeomfang, insidens, prevalens og skademekanismer samt letalitet og dødsårsaker ved traumatiske ryggmargsskader.
\end{abstract}

Kunnskapsgrunnlag. Det ble gjort litteratursøk i PubMed med søkeordene «traumatic spinal cord injury»/«traumatic spinal cord injuries» sammen med «epidemiology» og med «spinal cord injury»/«spinal cord injuries» sammen med «epidemiology».

Resultater. Rapportert årlig insidens av traumatisk ryggmargsskade varierer fra 2,3 per million i en studie fra Canada til 83 per million i Alaska. Prevalensen oppgis fra 236 per million i India til 1800 i USA. Gjennomsnittsalderen ved skade varierer fra 26,8 år i Tyrkia til 55,5 år i USA. Forholdet menn : kvinner varierer fra 0,9 på Taiwan til 12,0 i Nigeria. De hyppigste årsakene til skade er trafikk- og fallulykker. Pasienter med traumatisk ryggmargsskade har økt letalitet sammenliknet med normalbefolkningen. De viktigste dødsårsakene i dag er luftveisproblemer, hjertesykdom og selvmord.

Fortolkning. Det er store geografiske forskjeller i rapportert insidens, prevalens og letalitet. Dette skyldes ulikheter i definisjon, inklusjon, klassifisering og prosedyrer for pasientidentifisering i de ulike studiene, dessuten geografiske og kulturelle ulikheter og ulikheter i prehospital og hospital behandling.

\section{Ellen Merete Hagen}

ellen.merete.hagen@helse-bergen.no

Nevrologisk avdeling

Haukeland universitetssykehus

og

Institutt for klinisk medisin

Universitet i Bergen

\section{Tiina Rekand}

Spinalenheten

Nevrologisk avdeling

Haukeland universitetssykehus

\section{Nils Erik Gilhus}

Nevrologisk avdeling

Haukeland universitetssykehus

og

Institutt for klinisk medisin

Universitet i Bergen

\section{Marit Grønning}

Yrkesmedisinsk avdeling

Haukeland universitetssykehus og

Institutt for klinisk medisin

Universitet i Bergen

Traumatisk ryggmargsskade er per definisjon en akutt skade av ryggmargen som resulterer i varierende grad av sensoriske forstyrrelser og pareser (1). Skader på cauda equina er inkludert i definisjonen, men andre isolerte skader av nerverøtter er ekskludert (2). Tilstanden kan føre til livsvarig tap av funksjon og redusert livskvalitet samt økt sykelighet og dødelighet. Kunnskap om insidens, prevalens og kliniske konsekvenser er viktig for planlegging av behandlingsog omsorgstiltak for denne pasientgruppen både $\mathrm{i}$ sykehus og $\mathrm{i}$ kommunene, og kjennskap til skademekanismene er viktig i det forebyggende arbeidet. I denne artikkelen gis en oversikt over demografi, skadenivå, skadeomfang, insidens, prevalens og skademekanismer samt letalitet og dødsårsaker ved traumatiske ryggmargsskader.

\section{Kunnskapsgrunnlag}

Vi har gjort litteratursøk i PubMed med følgende kombinasjoner: «traumatic spinal cord injury AND epidemiology», «traumatic spinal cord injuries AND epidemiology», «spinal cord injuries AND epidemiology» og «spinal cord injuries AND epidemiology». Søket var avgrenset til artikler utgitt før 1.4. 2011, men det var ikke begrenset bakover i tid. Det var ingen avgrensning når det gjaldt språk, alder på skadetidspunktet eller design, men artiklene måtte være tilgjengelige i fulltekst enten via Internett eller via Universitetsbiblioteket i Bergen.
Søk på «traumatic spinal cord injury AND epidemiology» ga 140 artikler, hvorav fire oversiktsartikler. Søk på «traumatic spinal cord injuries AND epidemiology» ga 38 artikler, hvorav en oversiktsartikkel. Søk på «spinal cord injury AND epidemiology» ga 1346 artikler, hvorav 186 oversiktsartikler. Søk på «spinal cord injuries AND epidemiology» ga 1833 artikler, hvorav 243 oversiktsartikler.

Abstraktet til alle artikler med relevant tittel ble gjennomgått. Der abstraktet var relevant, ble den fullstendige teksten innhentet der den var tilgjengelig. Artikler som inkluderte spesielle aldersgrupper (f.eks. kun barn eller kun eldre pasienter) ble ikke tatt med i oversikten over studier om insidens og prevalens. De fleste populasjonsbaserte studiene inkluderte kun pasienter over 16 år, bare et fătall dekker alle aldersgrupper.

Etter gjennomgang av litteratur i fulltekst utgitt før april 2011 identifiserte vi 78 artikler som omhandler insidens (1,3-79), 17 artikler om prevalens $(5,10,11,38,40-42$, 80-89), 73 med alder ved skadetidspunktet $(1,3,5-12,14,17-25,27,30,31,33-37$, $39,40,44,46,47,51,52,57-66,68-75,85$, 90-108), 99 med kjønnsfordeling $(1,3-12$, $14,15,17-25,27-40,42,44,45,47,48$, 50-54, 57-79, 85, 90-118), 93 med skademekanismer $(1,3-6,8-12,14,15,17-22$, $24,25,27,28,30-41,44,45,47,48,50-54$, 57-70, 72-79, 92-98, 100-104, 107, 108, $110,111,113-125), 42$ med letalitet $(1,6$, $19,25,29,40,64,65,73,75,88,99,100$, $102,103,107,109,111,114,121,123$, 126-146), 105 med skadenivå $(1,3-79,85$, $90-118)$, sju med klinisk bilde $(20,24,90$, 147-150) og 15 artikler om dødsårsaker (6, $75,80,123,127,129,137,151-158)$. Tre av de inkluderte publikasjonene er ikke indek-

\section{Hovedbudskap}

- Det er store variasjoner i insidens og prevalens av traumatiske ryggmargsskader i verden

- De hyppigste årsakene til skade er trafikk- og fallulykker

- Pasientene har økt risiko for tidlig død, og livslang oppfølging er viktig

- De viktigste dødsårsakene i dag er luftveisproblemer, hjertesykdom og selvmord 
sert i PubMed, men er tatt med for å gi en så fullstendig oversikt som mulig $(38,78,91)$.

Artiklene ble valgt ut og data ekstrahert av førsteforfatter (EMH). Utvalget er basert på forfatterens kunnskap innenfor feltet og på hvilke artikler som er inkludert i internasjonale oversikter. Det er utgitt flere oversiktsartikler om dette temaet på engelsk i de senere år. I denne artikkelen er det særlig benyttet oversiktsartiklene til Cripps og medarbeidere (159), Wyndaele \& Wyndaele (160), van den Berg og medarbeidere (161) og Chiu og medarbeidere (162).

\section{Epidemiologi}

Det er rapportert store forskjeller i insidens, prevalens, kjønnsfordeling, skadeårsak, skadenivå og omfang av skade for traumatiske ryggmargsskader i ulike deler av verden (159-163).

\section{Insidens}

Årlig insidens er oppgitt til fra 2,3 per million i en studie fra Canada til 83 per million i Alaska (tab 1) $(1,3-79,85,90-118)$. Dette skyldes ulikheter i definisjon, inklusjon, klassifisering og prosedyrer i pasientidentifisering samt geografiske og kulturelle ulikheter $(163,164)$. Risikoen for traumatiske ryggmargsskader er 2,5 ganger høyere i landdistrikter enn i byer (36).

Også innen Europa er det store forskjeller. Høyeste rapporterte insidens er fra Portugal (57,8 per million) (25) og Russland (44,0 per million) (32), lavest er den i Italia (2,3 per million) (21). Fra Norge foreligger det tre insidensstudier (5-7). Gjone \& Nordlie fant en insidens på 16,5 per million innbygger i 1974-75 (7), Lidal og medarbeidere en insidens på 4,5 per million innbygger i perioden 1961-82 (6). I vår studie fra Sogn og Fjordane og Hordaland var det en insidens på 13,9 for perioden 1952-2001 (5). Den gjennomsnittlige årlige insidensen økte fra 5,9 per million i perioden 1952-1961 til 21,2 per million i perioden 1992-2001 (5). Insidensen av traumatiske ryggmargsskader forårsaket av trafikkulykker økte i løpet av observasjonsperioden, spesielt hos menn under 30 år. Når det gjelder traumatiske ryggmargsskader forårsaket av fallulykker, var det økt insidens hos menn over 60 år (5).

\section{Prevalens}

Det foreligger relativt få prevalensstudier av traumatiske ryggmargsskader (tab 2) $(5,10$, $11,38,40-42,80-89$ ). Lavest prevalens er det i India, med 236 per million (86), høyest er det i USA, med 1800 (84). Det eksisterer kun tre prevalensstudier fra Europa, alle fra Norden. Dahlberg og medarbeidere fant en prevalens på 280 per million i Helsingfors i 1999 (10), Knutsdottir fant en prevalens på 316 per million på Island i 1989 (11). Vi fant en prevalens på 365 per million innbyggere i fylkene Sogn og Fjordane og Hordaland i 2002 (5).

\section{Alder}

Gjennomsnittsalderen på skadetidspunktet varierer - fra 26,8 år i studien fra Tyrkia (98) til 55,5 år i Oklahoma, USA (51) (tab 1). I flere studier er det funnet en økning i gjennomsnittsalder på skadetidspunktet de siste tiårene, spesielt er det et økende antall perso- ner over 60 år som skader seg. I databasen National Spinal Cord Injury Statistical Center (USA) var gjennomsnittsalder ved skadetidspunktet 29 år i 1970 og 37 år i 2005 (91, 165). Andelen som skader seg etter fylte 60 år økte fra $5 \%$ til $13 \%$ i samme periode (165).

Vi fant at på Vestlandet økte gjennomsnittsalderen fra 40,2 år i perioden 1952-56 til 48,9 år i perioden 1997-2001, for kvinner fra 24,7 år til 57,7 år og for menn fra 41,5 år til 46,3 år (5).

\section{Kjønn}

Det er store variasjoner når det gjelder kjønnsfordelingen (tab 1). De fleste studier viser en overvekt av menn. I studier fra Taiwan og Iran er det like stor forekomst av traumatiske ryggmargsskader hos begge kjønn $(71,85)$. Størst overvekt av menn finner vi i studier fra Sierra Leone og Nigeria (ratio 11-12:1) $(64,100)$. I Norge har de tre studiene vist en mann-kvinne-ratio på $4,7-5,0: 1(5-7)$.

\section{Skademekanismer}

Den europeiske ryggmargsskadeorganisasjonen (ISCoS) og den tilsvarende amerikanske (ASIA) har sammen utviklet et internasjonalt datasett for registrering av ryggmargsskader (166). I Norge bruker vi ICD10 (International Classification of Diseases, versjon 10) som diagnosekodeverk. ICD-10 inneholder også koder for registrering av ytre årsaker til sykdommer, skader og dødsfall, men er ikke tatt $\mathrm{i}$ bruk i alle land, i USA for eksempel bruker man fortsatt ICD-9. Inndeling av skademekanismene ved rygg-

Tabell 1 Oversikt over rapporterte årlige insidenser lantall per million innbyggere), alder ved skade og kjønnsfordeling for traumatiske ryggmargsskader fordelt på geografiske regioner. Refererte studier rapporterer en eller flere av følgende variabler: insidens, alder ved skade og kjønnsfordeling

\begin{tabular}{|c|c|c|c|c|}
\hline Region & Observasjonsperiode & Insidenser & Alder ved skade (år) & Kjønnsfordeling (m : k) \\
\hline Norden $(1-10)$ & $1952-2008$ & $4,5-26,3$ & $27,9-47,9$ & $2,7-5,0$ \\
\hline Vest-Europa $(6,11-27)$ & $1960-2007$ & $2,3-57,8$ & $34,5-50,0$ & $1,6-7,7$ \\
\hline Sentral-Europa $(28,29)$ & $1975-2008$ & $14,5-28.5$ & 44,2 & $2,8-3,3$ \\
\hline Øst-Europa $(30,31)$ & $1989-96$ & $29,7-44,0$ & 34,2 & $1,8-3,6$ \\
\hline Alaska (32) & $1991-93$ & - & 35,0 & 5,0 \\
\hline Canada $(33-38,109)$ & $1947-2002$ & $2,3-52,5$ & $34,5-42,2$ & $1,5-4,5$ \\
\hline USA $(39-62,110,111)$ & $1970-2005$ & $23,7-77,0$ & $28,7-55,5$ & $1,0-5,6$ \\
\hline Latin-Amerika (63-66) & $1986-2002$ & - & $30,3-37,5$ & $4,1-6,3$ \\
\hline Oseania (67) & $1985-94$ & - & 38,3 & 6,5 \\
\hline Nord-Afrika/Midtøsten $(68-76,112)$ & $1974-2008$ & $12,1-44,0$ & $26,8-35,5$ & $1,0-8,3$ \\
\hline Vest-Afrika $(77-84,113,114)$ & $1973-2008$ & 3,4 & $30,0-37,9$ & $2,0-12,0$ \\
\hline Sørlige Afrika $(85-87,115)$ & $1963-94$ & $11,7-48,5$ & $28,0-35,6$ & $3,5-9,0$ \\
\hline Stillehavs-Asia $(88,89)$ & $1988-92$ & $28,6-40,2$ & 48,6 & $4,1-4,5$ \\
\hline$\emptyset$ st-Asia $(90-96,116)$ & $1977-2008$ & $14,6-73,0$ & $36,2-54,6$ & $0,9-7,5$ \\
\hline Sørøst-Asia (97) & $1989-94$ & - & 32,8 & 5,6 \\
\hline Sør-Asia $(98-104,117)$ & $1994-2007$ & - & $28,3-32,8$ & $1,8-7,6$ \\
\hline Australasia $(105-108,118)$ & $1978-2007$ & $14,5-49,1$ & - & $2,7-4,9$ \\
\hline
\end{tabular}


margsskader har derfor variert i den internasjonale litteraturen, men i de fleste studier har man delt skademekanismene inn i kategoriene trafikkulykker, fallulykker, sportsulykker og andre ulykker (159-163).

I de fleste land er trafikkulykker vanligst (159-163). Høyest andel er observert i VestAfrika, med $89 \%$ (113). Lavest er den på Grønland, med 4\% (3), og i Pakistan og Nepal, begge med $7 \%(76,117)$.

Fallulykker er den andre hovedmekanismen ved traumatiske ryggmargsskader (159-163). Disse omfatter alt fra fall fra stor høyde på arbeidsplassen eller i suicidal hensikt til at pasienten skled på badegulvet hjemme (5). Lavest andel er rapportert fra Sør-Afrika, med $3 \%$ (115), høyest i Pakistan og Nepal, begge med $82 \%(76,117)$. På Vestlandet var de hyppigste skademekanismene fallulykker $(45,5 \%)$ og trafikkulykker $(34,2 \%)(5)$.

Vold er en hyppig årsak til traumatiske ryggmargsskader i Sør-Afrika, der de utgjør $61-62 \%(66,115)$, mens samtlige studier i Europa rapporterer under $5 \%$ - unntatt Grønland, der vold var årsaken i $11 \%$ av tilfellene (3). Vold i form av hovedsakelig skuddskader har i USA vært årsaken til $12-23 \%$ av de traumatiske ryggmargsskadene, med en topp i første halvdel av 1990-årene (165).

Sportsulykker som fører til ryggmargsskader inntreffer hyppigst under stuping, turn og rugby (159-163). I Russland ble det rapportert at $33 \%$ av alle ulykkene skyldtes turn (31), i Australia har stupeulykkene vært dominerende (167). Et økende antall mennesker blir skadet i paragliderulykker (168).

De store variasjonene i skademekanisme i ulike studier kan dels skyldes geografiske og kulturelle forskjeller, men forskjellige definisjoner, forskjellig måte å samle inn data på og forskjellig studiedesign kan også forklare noe av variansen.

\section{Anatomisk skadenivå og skadeomfang}

Skadenivå

Det anatomiske skadenivået $\mathrm{i}$ ryggmargen deles inn i høye (cervikale) og lave skader (torakale, lumbale og sakrale) $(2,169)$. Det nevrologiske skadenivået defineres som det mest kaudale ryggmargssegmentet med normal funksjon $(2,169)$. Den nevrologiske vurderingen er viktig for klinisk diagnose, overvåking og prediksjon av funksjonelle utfall. Hos $10-15 \%$ av pasientene med traumatiske ryggmargsskader er det forskjell mellom det anatomiske og det nevrologiske skadenivået pga. skade i flere nivåer, vaskulære forandringer og/eller ødem i ryggmargen etter skaden (170). Det nevrologiske skadenivået klassifiseres i henhold til American Spinal Injury Association (ASIA) Impairment Scale A-E $(169,171)$ (ramme 1).

Andelen høye (cervikale) og lave (torakale eller lumbosakrale) skader varierer i ulike studier. Fra Kina er det rapportert at $5 \%$ av pasientene har høye skader (69), mot
$92 \%$ i Tyrkia (98). Disse variasjonene mellom landene kan delvis forklares på bakgrunn av ulikt årsaksmønster, men behandlingstilgjengelighet, både geografisk og økonomisk, bidrar nok til en generell underrapportering av traumatiske ryggmargsskader i mange land. Vi tror at pasienter med nakkeskader vil ha reduserte muligheter for å nå frem til sykehus i live pga. sosioøkonomiske forhold i mange land (f.eks. Kina).

\section{Letalitet}

Letalitet defineres som forholdstallet mellom antall døde av en bestemt sykdom eller skade og det totale antall tilfeller av sykdommen eller skaden i et gitt tidsintervall. I den vestlige verden har letaliteten som følge av traumatisk ryggmargsskade i den akutte fasen sunket fra $30 \%$ i 1960-årene til $6 \%$ i 1980-årene $(135,152)$. Til tross for dette har pasienter med traumatiske ryggmargsskader fortsatt økt risiko for tidlig død (172-175). Standardisert mortalitetsratio (SMR) er forholdet mellom observerte dødsfall og forventede dødsfall i en referansebefolkning. I en finsk studie var det økt risiko for død hos pasienter med traumatiske ryggmargsskader, med en standardisert mortalitetsratio på 3,56 for kvinner og 2,54 for menn (128). Lidal og medarbeidere fant en standardisert mortalitetsratio på 1,8 for menn og 4,9 for kvinner med traumatiske ryggmargsskader innlagt ved Sunnaas sykehus (6).

I vår studie fra Vestlandet fant vi at pasienter med traumatiske ryggmargsskader hadde en økt risiko på 1,85 (SMR) for å dø, sammenliknet med andre av samme kjønn og alder (129). Standardisert mortalitetsratio var høyest de første ti år etter skaden. Gruppen med komplett skade hadde kortere gjen-

\section{Ramme 1}

\section{The American Spinal Injury Association (ASIA) Impairment Scale A-E (169)}

- ASIA A - ingen muskelfunksjon og ingen følelse under skadenivået i ryggmargen

- $A S I A B$ - ingen motorisk funksjon under skadenivået

- $A S I A C$ - bevart motorisk og sensorisk funksjon under skadenivået, men for lite til at dette gir praktisk nyttig funksjon

- ASIAD-muskelfunksjon og sensorisk funksjon under skadenivået som gir praktisk nyttig funksjon Istyrkenivå 3 eller bedre på en skala fra 0 til 5 i $50 \%$ av musklene under skadenivået)

- $A S I A E$ - ubetydelige nevrologiske begrensninger som følge av ryggmargsskaden $(169,171)$

ASIA A innebærer komplett skade, ASIA $B-D$ er inkomplette skader

nomsnittlig forventet levetid enn gruppen med inkomplett skade (SMR 4,23 versus SMR 1,25). Kvinner hadde redusert forventet levetid sammenliknet med menn (SMR 2,88 versus SMR 1,72). Gjennomsnittlig tid fra skade til død var 6,9 år for pasienter med nakkeskader og 8,2 år for pasienter med lavere skader (129).

Pasienter med ryggmargsskader i Danmark hadde en betydelig nedgang i dødelig-

Tabell 2 Oversikt over rapportert prevalens (antall per million innbyggere) av traumatiske ryggmargsskader, fordelt på geografiske regioner

\begin{tabular}{lcc}
\hline Region & Observasjonsperiode & Prevalens \\
\hline Norden $(5,10,11)$ & $1973-2002$ & $280-365$ \\
\hline Vest-Europa & - & - \\
\hline Sentral-Europa & - & - \\
Øst-Europa & - & 1173 \\
\hline Canada (38) & $2001-02$ & $473-1800$ \\
USA (40-42, 80-84) & $1935-94$ & - \\
\hline Latin-Amerika & - & - \\
\hline Oseania & - & 440 \\
\hline Nord-Afrika/Midtøsten (85) & $2003-08$ & - \\
\hline Vest-Afrika & - & - \\
\hline Sørlige Afrika & - & - \\
\hline Stillehavs-Asia & - & - \\
\hline$\emptyset$ st-Asia & - & - \\
\hline Sørøst-Asia & - & 236 \\
\hline Sør-Asia (86) & 1986 & -680 \\
\hline Australasia (87-89) & $1987-98$ & - \\
& & \\
\hline
\end{tabular}


Tabell 3 Oversikt over rapportert letalitet innen ett år og mer enn ti år etter traumatisk ryggmargsskade, fordelt på geografiske regioner

\begin{tabular}{|c|c|c|c|}
\hline Region & $\begin{array}{l}\text { Observasjons- } \\
\text { periode }\end{array}$ & $\begin{array}{c}\text { 1-årsletalitet } \\
{[\%]}\end{array}$ & $\begin{array}{c}\geq 10 \text {-årsletalitet } \\
{[\%]}\end{array}$ \\
\hline Norden $(6,126-129)$ & $1952-2008$ & $0,0-2,5$ & $2,5-43,4$ \\
\hline Vest-Europa $(19,25,126,130-132)$ & $1948-2007$ & $18,8-56,0$ & $7,1-50,0$ \\
\hline Sentral-Europa (29) & $2005-08$ & 10,3 & - \\
\hline Øst-Europa & - & - & - \\
\hline Alaska & - & - & - \\
\hline Canada $(109,121,133)$ & $1975-2007$ & 4,0 & $3,0-10,7$ \\
\hline USA $(1,40,111,123,134-141)$ & $1940-2004$ & $8,0-61,0$ & $14,3-53,9$ \\
\hline Latin-Amerika $(142,143)$ & $1986-2005$ & $10,9-29,2$ & - \\
\hline Oseania & - & - & - \\
\hline Nord-Afrika/Midtøsten & - & - & - \\
\hline Vest-Afrika $(64,99,100,102,114,144,145)$ & $1973-2008$ & $11,0-84,0$ & 83,0 \\
\hline Sørlige Afrika $(65,103)$ & $1963-94$ & $13,0-49,0$ & - \\
\hline Stillehavs-Asia & - & - & - \\
\hline Øst-Asia (73) & $1986-90$ & 10,1 & - \\
\hline Sørøst-Asia (75) & $1989-94$ & 16,0 & - \\
\hline Sør-Asia (107) & $2003-07$ & 10,7 & - \\
\hline Australasia $(88,146)$ & $1955-98$ & 5,7 & $9,0-14,3$ \\
\hline
\end{tabular}

het sammenliknet med normalbefolkningen fra perioden 1953-71 til 1972-92 (127).

Tidlig død defineres som død etter skade innen 30 dager (176). De fleste oppfølgingsstudiene om traumatiske ryggmargsskader kommer fra rehabiliteringssentre som mottar pasientene mange måneder etter skadetidspunktet. I mange studier har man derfor valgt å ekskludere alle som dør innen ett år etter skaden og definerer ett år etter skadetidspunktet som skillet mellom tidlig og sen død $(6,165)$.

Tabell 3 er en oversikt over rapportert letalitet innen ett år og mer enn ti år etter traumatisk ryggmargsskade, fordelt på geografiske regioner. I disse studiene er kun pasienter som kom til sykehuset i live inkludert. Norden har den laveste rapporterte letaliteten innen ett år etter skade (tab 3) $(1,6,19,25$, $29,40,64,65,73,75,88,99,100,102,103$, $107,109,111,114,121,123,126-146)$

\section{Dødsårsaker}

Dødsårsaker er definert som sykdommer eller skader som enten direkte eller indirekte er årsak til dødsfallene i en befolkning. I Norge er det Statistisk sentralbyrå som utarbeider den offisielle dødsårsaksstatistikken. Eurostat har utarbeidet en europeisk kortliste av ICD10. Listen er laget for internasjonal sammenlikning av dødsårsaker. Den består av 65 dødsårsaksgrupper og kan benyttes for ICD-9 og ICD-8 i tillegg til ICD-10 (177).

De siste 50 år er årsakene til sen død etter ryggmargsskade vesentlig endret. Tidligere var urosepsis den vanligste dødsårsaken etter traumatiske ryggmargsskader (157), mens de viktigste i dag er luftveisproblemer, hjertesykdom og selvmord (129). Lungebetennelse er den vanligste dødsårsaken hos pasienter med cervikale ryggmargsskader og hos papig årsak til dødsfall hos pasienter med torakale, lumbale og sakrale skader (178).

I en dansk studie var de vanligste dødsårsakene lungesykdommer (særlig lungebetennelse), selvmord og iskemisk hjertesykdom (127). For pasienter innlagt i Sunnaas sykehus i perioden 1961-82 var de hyppigste dødsårsakene lungebetennelse eller influensa hos $16 \%$, iskemisk hjertesykdom hos $13 \%$ og urogenital sykdom hos $13 \%$ (6).

I en studie fra Vestlandet var årsaksspesifikk standardisert mortalitetsratio 1,96 (95\% KI 1,22-3,15) for lungesykdom og $5,79(95 \%$ KI 3,11-10,75) for selvmord og forgiftning (129). Kvinner hadde betydelig høyere samlet standardisert mortalitetsratio for selvmord og forgiftning. Risikoen for å dø av lungesykdom var høyest hos pasienter med nakkeskader, mens selvmord og forgiftning også i denne studien forekom hyppigst hos dem med lave, inkomplette skader (129).

\section{Barn med ryggmargsskade}

Det foreligger svært få populasjonsbaserte studier som inkluderer barn. I en finsk studie ble gjennomsnittlig årlig insidens estimert til 1,9 per million i aldersgruppen $0-18$ år i perioden 1997-2006 (179). I en svensk studie var det en årlig insidens på 4,6 per million barn (120).

I studien fra Vestlandet var 3,9\% av de sienter over 60 år (54). Selvmord er en hyp- skadede barna 0 -14 år på skadetidspunktet, $13,1 \%$ var $15-19$ år (180). Hovedmekanismen bak skade hos barn var bil- og fotgjengerulykker, ungdommer ble skadet i bil- og motorsykkelulykker. Insidensen av traumatiske ryggmargsskader hos barn har holdt seg lav, mens insidensen hos ungdom har økt betydelig i løpet av de siste 50 år (180).

\section{Eldre med ryggmargsskade}

Hos eldre pasienter med traumatiske ryggmargsskader er det økt forekomst av komplikasjoner, høyere dødelighet, dårligere prognose og lavere rehabiliteringspotensial enn hos yngre (181, 182).

I vår studie fra Vestlandet undersøkte vi skademekanismene hos pasienter som ble skadet etter fylte 60 år og som ble rehabilitert ved Nevrologisk avdeling, Haukeland universitetssykehus, i perioden 1952-2001 (183). Andelen eldre økte de siste fem årene av studieperioden. Den hyppigste skademekanismen var fall (77\%). For over en tredel var fallhøyden på under en meter. $80 \%$ fikk inkomplette skader og oppnådde betydelig funksjonsbedring i løpet av det primære rehabiliteringsoppholdet (183).

\section{Hodeskade og ryggmargsskade}

Pasienter som har fått en hodeskade samtidig med en traumatisk ryggmargsskade, har ytterligere økt sykelighet og behov for kompleks rehabilitering (184).

Forekomsten av hodeskade varierer fra $26 \%$ til $74 \%$ i ulike pasientpopulasjoner med traumatisk ryggmargsskade $(185,186)$. I en prospektiv studie fant man at $34 \%$ av dem med traumatisk ryggmargsskade hadde en mild hodeskade og at $26 \%$ hadde en alvorlig hodeskade (185). De som blir skadet i trafikk- og fallulykker hadde særlig økt risiko for å få en samtidig hodeskade. Hodeskader var særlig assosiert med cervikal ryggmargsskade.

I vår studie fra Vestlandet hadde 46,7 \% av pasientene med traumatisk ryggmargsskade også en klinisk hodeskade (147). Hodeskaden ble vurdert å være mild hos $30,1 \%$, moderat hos $11,0 \%$ og alvorlig hos $5,7 \%$. Alkohol var den største risikofaktoren for hodeskade $(\mathrm{OR}=3,69)(147)$.

\section{Konklusjon}

Det er store geografiske forskjeller i rapportert insidens, prevalens og letalitet for traumatiske ryggmargsskader. Dette skyldes ulikheter i definisjon, inklusjon, klassifisering og prosedyrer i pasientidentifisering, geografiske og kulturelle ulikheter samt ulikheter i tilgjengelig prehospital og hospital behandling.

Vi tror at bedret tilgjengelighet til prehospital behandling har bidratt til at flere pasienter kommer inn i sykehuset $i$ live i dag enn tidligere. Dette har ført til en økning i prevalens, insidens og tidlig overlevelse. Forskjellene i skademekanismer, alder og kjønnsfordeling mellom ulike land avspeiler ulikheter $\mathrm{i}$ 
kultur og levemåte og forskjellig befolkningssammensetning.

I Norge har insidensen av traumatiske ryggmargsskader økt de siste 50 år. Hyppigste skademekanismer er trafikkulykker og fallulykker. Det er et særlig behov for forebyggende tiltak rettet mot trafikkulykker hos unge gutter og menn, dessuten trengs det tiltak rettet mot forebygging av fallulykker hos eldre. Helsevesenet må ta utfordringen som ligger i en økende andel eldre pasienter med inkomplette nakkeskader, ikke minst fordi denne gruppen har svært god nytte av høyspesialisert rehabilitering.

Pasienter med traumatiske ryggmargsskader har til tross for bedret diagnostikk og behandling fortsatt betydelig økt dødelighet sammenliknet med befolkningen for øvrig. Mer kunnskap hos helsepersonell om senfølger og komplikasjoner etter ryggmargsskader er viktig for å redusere komplikasjonene, øke overlevelsen og bedre livskvaliteten hos disse pasientene.

\section{Ellen Merete Hagen (f. 1962)}

er ph.d. og spesialist i nevrologi og i samfunnsmedisin. Hun har doktorgrad på epidemiologi ved traumatiske ryggmargsskader og er nå postdoktor ved Universitetet i Bergen.

Forfatter har fylt ut ICMJE-skjemaet og oppgir ingen interessekonflikter.

\section{Tiina Rekand (f. 1960)}

er dr.med. og spesialist i nevrologi. Hun er overlege ved Spinalenheten ved Nevrologisk avdeling. Haukeland universitetssykehus, og medlem i styret for det norske ryggmargsskaderegisteret.

Forfatter har fylt ut ICMJE-skjemaet og oppgir ingen interessekonflikter.

\section{Nils Erik Gilhus (f. 1950)}

er professor og overlege i nevrologi ved Universitetet i Bergen og Haukeland universitetssykehus. Han er leder ved Institutt for klinisk medisin, Universitetet i Bergen.

Forfatter har fylt ut ICMJE-skjemaet og oppgir ingen interessekonflikter.

\section{Marit Grønning (f. 1955)}

er spesialist og professor II i nevrologi. Hun var i ti år overlege ved Spinalenheten ved Haukeland universitetssykehus.

Forfatter har fylt ut ICMJE-skjemaet og oppgir ingen interessekonflikter.

\section{Litteratur}

1. Kraus JF, Franti CE, Riggins RS et al. Incidence of traumatic spinal cord lesions. J Chronic Dis 1975; 28: $471-92$

2. Maynard FM jr., Bracken MB, Creasey $G$ et al. International standards for neurological and functional classification of spinal cord injury. Spinal Cord 1997; 35: 266-74

3. Pedersen V, Müller PG, Biering-Sørensen F. Traumatic spinal cord injuries in Greenland 1965-1986. Paraplegia 1989; 27: 345-9.

4. Biering-Sørensen E, Pedersen V, Clausen S. Epidemiology of spinal cord lesions in Denmark. Paraplegia 1990; 28: 105-18.
5. Hagen EM, Eide GE, Rekand T et al. A 50-year follow-up of the incidence of traumatic spinal cord injuries in Western Norway. Spinal Cord 2010; 48: 313-8.

6. Lidal IB, Snekkevik H, Aamodt G et al. Mortality after spinal cord injury in Norway. J Rehabil Med 2007; 39: 145-51.

7. Gjone R, Nordlie L. Incidence of traumatic paraplegia and tetraplegia in Norway: a statistical survey of the years 1974 and 1975. Paraplegia 1978; 16: 88-93.

8. Divanoglou A, Levi R. Incidence of traumatic spinal cord injury in Thessaloniki, Greece and Stockholm, Sweden: a prospective populationbased study. Spinal Cord 2009; 47: 796-801.

9. Ahoniemi E, Alaranta H, Hokkinen EM et al. Incidence of traumatic spinal cord injuries in Finland over a 30-year period. Spinal Cord 2008; 46: $781-4$.

10. Dahlberg A, Kotila M, Leppänen P et al. Prevalence of spinal cord injury in Helsinki. Spinal Cord 2005; 43: 47-50.

11. Knútsdóttir S. Spinal cord injuries in Iceland 1973-1989. A follow up study. Paraplegia 1993; 31: $68-72$

12. Knutsdottir S, Thorisdottir H, Sigvaldason $\mathrm{K}$, et al Epidemiology of traumatic spinal cord injuries in Iceland from 1975 to 2009. Spinal Cord 2012 50: $123-6$

13. Albert T, Ravaud JF. Rehabilitation of spinal cord injury in France: a nationwide multicentre study of incidence and regional disparities. Spinal Cord 2005; 43: 357-65.

14. Minaire P, Castanier M, Girard R et al. Epidemiology of spinal cord injury in the Rhône-Alpes region, France, 1970-75. Paraplegia 1978; 16: 76-87.

15. Exner G, Meinecke FW. Trends in the treatment of patients with spinal cord lesions seen within a period of 20 years in German centers. Spinal Cord 1997; 35: 415-9.

16. Köning W. Frowein RA. Incidence of spinal cord injury in the Federal Republic of Germany. Neurosurg Rev 1989; 12 (suppl 1): 562-6.

17. O'Connor RJ, Murray PC. Review of spinal cord injuries in Ireland. Spinal Cord 2006; 44: 445-8

18. Roche SJ, Sloane PA, McCabe JP. Epidemiology of spine trauma in an Irish regional trauma unit: a 4-year study. Injury 2008; 39: 436-42.

19. Catz A, Thaleisnik M, Fishel B et al. Survival following spinal cord injury in Israel. Spinal Cord 2002; 40: 595-8

20. Pagliacci MC, Celani MG, Zampolini M et al. An Italian survey of traumatic spinal cord injury. The Gruppo Italiano Studio Epidemiologico Mielo lesioni study. Arch Phys Med Rehabil 2003; 84 $1266-75$.

21. Celani MG, Spizzichino L, Ricci S et al. Spinal cord injury in Italy: a multicenter retrospective study. Arch Phys Med Rehabil 2001; 82: 589-96.

22. Caldana L, Lucca L. Epidemiological remarks on traumatic spinal cord injuries and non-traumatic spinal cord diseases in Veneto 1994-1995. Eura Medicophys 1998; 34: 159-68

23. Schönherr MC, Groothoff JW, Mulder GA et al. Rehabilitation of patients with spinal cord lesions in The Netherlands: an epidemiological study. Spinal Cord 1996; 34: 679-83

24. van Asbeck FWA, Post MWM, Pangalila RF. An epidemiological description of spinal cord injuries in The Netherlands in 1994. Spinal Cord 2000; 38: 420-4.

25. Martins F, Freitas F, Martins L et al. Spinal cord injuries-epidemiology in Portugal's central region. Spinal Cord 1998; 36: 574-8.

26. Garcia-Reneses J, Herruzo-Cabrera R, MartinezMoreno M. Epidemiological study of Spinal Cord Injury in Spain 1984-1985. Paraplegia 1991; 29: 180-90.

27. Gehrig R, Michaelis LS. Statistics of acute paraplegia and tetraplegia on a national scale. Switzerland 1960-67. Paraplegia 1968; 6: 93-5.

28. Aung TS, el Masry WS. Audit of a British Centre for spinal injury. Spinal Cord 1997: 35: 147-50.

29. Pietraszkiewicz F, Tysiewicz-Dudek M. Epidemiology of spinal injuries in Lubuskie Province. Ortop Traumatol Rehabil 2010; 12: 435-42.

30. Soopramanien A. Epidemiology of spinal injuries in Romania. Paraplegia 1994; 32: 715-22.

31. Silberstein B, Rabinovich S. Epidemiology of spinal cord injuries in Novosibirsk, Russia. Paraplegia 1995; 33: 322-5
32. Kondakov EN, Simonova IA, Poliakov IV. [The epidemiology of injuries to the spine and spinal cord in Saint Petersburg]. Vopr Neirokhir 2002; nr. 2: $50-2$.

33. Warren S, Moore M, Johnson MS. Traumatic head and spinal cord injuries in Alaska (1991-1993). Alaska Med 1995; 37: 11-9.

34. Tator CH, Duncan EG, Edmonds VE et al. Changes in epidemiology of acute spinal cord injury from 1947 to 1981. Surg Neurol 1993: 40: 207-15.

35. Pickett W, Simpson K, Walker J et al. Traumatic spinal cord injury in Ontario, Canada. J Trauma 2003; 55: 1070-6.

36. Dryden DM, Saunders LD, Rowe BH et al. The epidemiology of traumatic spinal cord injury in Alberta, Canada. Can J Neurol Sci 2003; 30: $113-21$.

37. Pickett GE, Campos-Benitez M, Keller JL et al. Epidemiology of traumatic spinal cord injury in Canada. Spine 2006; 31: 799-805.

38. Rick Hansen Spinal Cord Injury Register. Spinal cord injury facts and statistics: Canada. Rick Hansen Spinal Cord Injury Register 2010. http://rickhansenregistry.org/en/ news-and-resources/sci-facts.html (11.1.2012).

39. Kalsbeek WD, McLaurin RL, Harris BS 3rd et al. The National Head and Spinal Cord Injury Survey: major findings. J Neurosurg 1980; 53 (suppl): S19-31

40. Stover SL, Fine PR. The epidemiology and economics of spinal cord injury. Paraplegia 1987; 25 225-8.

41. Ditunno JF Jr. Formal CS. Chronic spinal cord injury. N Engl J Med 1994; 330: 550-6

42. Lasfargues JE, Custis D, Morrone F et al. A model for estimating spinal cord injury prevalence in the United States. Paraplegia 1995; 33: $62-8$

43. Johnson RL, Gabella BA, Gerhart KA et al. Evaluating sources of traumatic spinal cord injury surveillance data in Colorado. Am J Epidemiol 1997; 146: $266-72$.

44. National Spinal Cord Injury Statistical Center. Spinal cord injury. Facts and figures at a glance. J Spinal Cord Med 2005; 28: 379-80.

45. Griffin MR, Opitz JL, Kurland LT et al. Traumatic spinal cord injury in Olmsted County, Minnesota, 1935-1981. Am J Epidemiol 1985; 121: 884-95.

46. Bracken MB, Freeman DH jr., Hellenbrand K. Incidence of acute traumatic hospitalized spinal cord injury in the United States, 1970-1977. Am J Epidemiol 1981; 113: 615-22.

47. Jackson AB, Dijkers M, Devivo MJ et al. A demographic profile of new traumatic spinal cord injuries: change and stability over 30 years. Arch Phys Med Rehabil 2004: 85: $1740-8$

48. Acton PA, Farley T, Freni LW et al. Traumatic spinal cord injury in Arkansas, 1980 to 1989. Arch Phys Med Rehabil 1993; 74: 1035-40.

49. Centers for Disease Control (CDC). Trends in traumatic spinal cord injury - New York 1982-1988. MMWR Morb Mortal Wkly Rep 1991; 40: $535-7,543$.

50. Goebert DA, Ng MY, Varney JM et al. Traumatic spinal cord injury in Hawaii. Hawaii Med J 1991. 50: 44, 47-8, 50

51. Price C, Makintubee S, Herndon W et al. Epidemiology of traumatic spinal cord injury and acute hospitalization and rehabilitation charges for spinal cord injuries in Oklahoma, 1988-1990. Am J Epidemiol 1994; 139: 37-47

52. Thurman DJ, Burnett $C L$, Jeppson $L$ et al. Sur veillance of spinal cord injuries in Utah, USA. Paraplegia 1994: 32: 665-9.

53. Surkin J, Gilbert BJ, Harkey HL 3rd et al. Spinal cord injury in Mississippi. Findings and evaluation, 1992-1994. Spine 2000; 25: 716-21.

54. Burke DA, Linden RD, Zhang YP et al. Incidence rates and populations at risk for spinal cord injury: A regional study. Spinal Cord 2001; 39: 274-8.

55. Buechner JS, Speare MC, Fontes J. Hospitalizations for spinal cord injuries, 1994-1998. Med Health R I 2000: 83: 92-3.

56. Barros Filho TE, Taricco MA, Oliveira RP et al. Epidemiological study of patients with spinal cord injuries and neurologic deficit, admitted to the Institute of Orthopedics and Traumatology at the Hospital das Clinicas of the School of Medicine of the University of São Paulo. Rev Hosp Clin Fac Med Sao Paulo 1990; 45: $123-6$. 
57. Maharaj JC. Epidemiology of spinal cord paralysis in Fiji: 1985-1994. Spinal Cord 1996; 34 549-59.

58. Otom AS, Doughan AM, Kawar JS et al. Traumatic spinal cord injuries in Jordan-an epidemiological study. Spinal Cord 1997; 35: 253-5.

59. Mena Quinones PO, Nassal M, Al Bader KI et al. Traumatic Spinal Cird Injury in Qatar: An Epidemiological Study. Middle East J Emerg Med 2002; 2: 67-9

60. Karacan I, Koyuncu H, Pekel $O$ et al. Traumatic spinal cord injuries in Turkey: a nation-wide epidemiological study. Spinal Cord 2000; 38: 697-701

61. Karamehmetoglu SS, Unal S, Karacan I et al. Traumatic spinal cord injuries in Istanbul, Turkey. An epidemiological study. Paraplegia 1995 33: 469-71.

62. Karamehmetoglu SS, Nas K, Karacan I et al. Traumatic spinal cord injuries in southeast Turkey: an epidemiological study. Spinal Cord 1997; 35: $531-3$.

63. Gur A, Kemaloglu MS, Cevik R et al. Characteristics of traumatic spinal cord injuries in south-eastern Anatolia, Turkey: a comparative approach to 10 years' experience. Int J Rehabil Res 2005; 28: 57-62.

64. Gosselin RA, Coppotelli C. A follow-up study of patients with spinal cord injury in Sierra Leone. Int Orthop 2005; 29: $330-2$.

65. Levy LF, Makarawo S, Madzivire D et al. Problems, struggles and some success with spinal cord injury in Zimbabwe. Spinal Cord 1998; 36: 213-8

66. Velmahos GC, Degiannis E, Hart K et al. Changing profiles in spinal cord injuries and risk factors influencing recovery after penetrating injuries. J Trauma 1995; 38: 334-7.

67. Ide M, Ogata H, Tokuhiro A et al. Spinal cord injuries in Okayama Prefecture: an epidemiological study '88-'89. J UOEH 1993; 15: 209-15.

68. Shingu $H$, Ohama M, Ikata T et al. A nationwide epidemiological survey of spinal cord injuries in Japan from January 1990 to December 1992. Paraplegia 1995; 33: 183-8

69. Li J, Liu G, Zheng Y et al. The epidemiological survey of acute traumatic spinal cord injury (ATSCI) of 2002 in Beijing municipality. Spinal Cord 2011; 49: 777-82

70. Ning GZ, Yu TQ, Feng $S Q$ et al. Epidemiology of traumatic spinal cord injury in Tianjin, China. Spinal Cord 2011; 49: 386-90.

71. Yang NP, Deng CY, Lee YH et al. The incidence and characterisation of hospitalised acute spinal trauma in Taiwan-a population-based study. Injury 2008; 39: 443-50.

72. Chen HY, Chen SS, Chiu WT et al. A nationwide epidemiological study of spinal cord injury in geriatric patients in Taiwan. Neuroepidemiology 1997; 16: $241-7$

73. Lan C, Lai JS, Chang KH et al. Traumatic spinal cord injuries in the rural region of Taiwan: an epidemiological study in Hualien county, 1986-1990. Paraplegia 1993; 31: 398-403

74. Chen CF, Lien IN. Spinal cord injuries in Taipei, Taiwan, 1978-1981. Paraplegia 1985; 23: 364-70.

75. Pajareya K. Traumatic spinal cord injuries in Thailand: an epidemiologic study in Siriraj Hospital, 1989-1994. Spinal Cord 1996; 34: 608-10.

76. Raja IA, Vohra AH, Ahmed M. Neurotrauma in Pakistan. World J Surg 2001; 25: $1230-7$.

77. O'Connor P. Incidence and patterns of spinal cord injury in Australia. Accid Anal Prev 2002; 34 405-15.

78. Cripps RA. Spinal cord injury, Australia, 2006-07. AIHW Cat No INJCAT 119 January 2009. www.nisu.flinders.edu.au/pubs/reports/2009/ injcat119.php (11.1.2012).

79. Dixon GS, Danesh JN, Caradoc-Davies TH. Epidemiology of spinal cord injury in New Zealand. Neuroepidemiology 1993; 12: 88-95.

80. Griffin MR, O'Fallon WM, Opitz JL et al. Mortality, survival and prevalence: traumatic spinal cord injury in Olmsted County, Minnesota, 1935-1981. J Chronic Dis 1985: 38: 643-53.

81. Harvey C, Rothschild BB, Asmann AJ et al. New estimates of traumatic SCI prevalence: a surveybased approach. Paraplegia 1990; 28: 537-44.

82. DeVivo MJ, Fine PR, Maetz HM et al. Prevalence of spinal cord injury: a reestimation employing life table techniques. Arch Neurol 1980; 37 707-8
83. Ergas Z. Spinal cord injury in the United States: a statistical update. Cent Nerv Syst Trauma 1985 2: $19-32$.

84. Kurtzke JF. Epidemiology of spinal cord injury. Neurol Neurocir Psiquiatr 1977; 18 (suppl): 157-91.

85. Rahimi-Movaghar V, Saadat S, Rasouli MR et al. Prevalence of spinal cord injury in Tehran, Iran. J Spinal Cord Med 2009; 32: 428-31.

86. Razdan S, Kaul RL, Motta A et al. Prevalence and pattern of major neurological disorders in rural Kashmir (India) in 1986. Neuroepidemiology 1994: 13: 113-9

87. Walsh J. Costs of spinal cord injury in Australia. Paraplegia 1988; 26: 380-8.

88. Yeo JD, Walsh J, Rutkowski S et al. Mortality following spinal cord injury. Spinal Cord 1998; 36: 329-36.

89. $0^{\prime}$ Connor PJ. Prevalence of spinal cord injury in Australia. Spinal Cord 2005; 43: 42-6.

90. Osterthun R, Post MW, van Asbeck FW. Characteristics, length of stay and functional outcome of patients with spinal cord injury in Dutch and Flemish rehabilitation centres. Spinal Cord 2009 47: 339-44.

91. National Spinal Cord Injury Statistical Center. Spinal cord injury facts and figures at a glance. Birmingham, Alabama, USA: The National Spinal Cord Injury Statistical Center, 2010 www.nscisc.uab.edu/public_content/pdf/ Facts $\% 20$ and $\% 20$ Figures $\% 20$ at $\% 20$ a\%20Glance \%202010.pdf (11.1.2012).

92. Nobunaga Al, Go BK, Karunas RB. Recent demographic and injury trends in people served by the Model Spinal Cord Injury Care Systems. Arch Phys Med Rehabil 1999; 80: 1372-82.

93. Calancie B, Molano MR, Broton JG. Epidemiology and demography of acute spinal cord injury in a large urban setting. J Spinal Cord Med 2005 28: $92-6$.

94. Ho CH, Wuermser LA, Priebe MM et al. Spinal cord injury medicine. 1. Epidemiology and classification. Arch Phys Med Rehabil 2007; 88 (suppl 1): S49-54

95. da Paz AC, Beraldo PS, Almeida MC et al. Traumatic injury to the spinal cord. Prevalence in Brazilian hospitals. Paraplegia 1992; 30: 636-40.

96. Brasil AVB, Coelho DG. The neurological outcome of acute spinal cord injury in a neurosurgical hospital of a developing country. Spinal Cord 1998; 36: 353-6.

97. Leal-Filho MB, Borges G, Almeida BR et al. Spinal cord injury: epidemiological study of 386 cases with emphasis on those patients admitted more than four hours after the trauma. Arq Neuropsiquiatr 2008: 66: 365-8

98. Dincer F, Oflazer A, Beyazova M et al. Traumatic spinal cord injuries in Turkey. Paraplegia 1992; 30: $641-6$

99. Emejulu JK, Ekweogwu OC. Outcome of spinal cord injuries managed in a centre without modern imaging facilities. West Afr J Med 2009; 28: $376-9$.

100. Solagberu BA. Spinal cord injuries in Ilorin, Nige ria. West Afr J Med 2002; 21: $230-2$

101. Obalum DC, Giwa SO, Adekoya-Cole TO et al. Profile of spinal injuries in Lagos, Nigeria. Spinal Cord 2009; 47: $134-7$.

102. Iwegbu CG. Traumatic paraplegia in Zaria, Nigeria: the case for a centre for injuries of the spine. Paraplegia 1983; 21: $81-5$

103. Key AG, Retief PJ. Spinal cord injuries. An analysis of 300 new lesions. Paraplegia 1970; 7: 243-9.

104. Hoque MF, Grangeon C, Reed K. Spinal cord lesions in Bangladesh: an epidemiological study 1994-1995. Spinal Cord 1999: 37: 858-61.

105. Singh R, Sharma SC, Mittal R et al. Traumatic spinal cord injuries in Haryana: an epidemiological study. Indian J Community Med 2003; 28 : 184-6.

106. Bajracharya S, Singh M, Singh GK et al. Clinicoepidemiological study of spinal injuries in a predominantly rural population of eastern Nepal: A 10 years' analysis. Indian J Orthop 2007; 41: $286-9$.

107. Masood Z, Wardug GM, Ashraf J. Spinal injuries: Experience of a local Neurosurgical Centre. Pak J Med Sci 2008; 24: 368-71.

108. Rathore MF. Hanif S, Faroog F et al. Traumatic spinal cord injuries at a tertiary care rehabilitation institute in Pakistan. J Pak Med Assoc 2008; 58: $53-7$.
109. Hu R, Mustard CA, Burns C. Epidemiology of incident spinal fracture in a complete population. Spine 1996; 21: 492-9.

110. Harvey C, Wilson SE, Greene CG et al. New estimates of the direct costs of traumatic spinal cord injuries: results of a nationwide survey. Paraplegia 1992; 30: 834-50

111. Burney RE, Maio RF, Maynard F et al. Incidence, characteristics, and outcome of spinal cord injury at trauma centers in North America. Arch Surg 1993; 128: 596-9.

112. Yousefzadeh Chabok S, Safaee M, Alizadeh A et al. Epidemiology of traumatic spinal injury: a descriptive study. Acta Med Iran 2010; 48: $308-11$.

113. Olasode BJ, Komolafe IE, Komolafe M et al. Traumatic spinal cord injuries in Ile-Ife, Nigeria, and its environs. Trop Doct 2006; 36: $181-2$.

114. Igun GO, Obekpa OP, Ugwu BT et al. Spinal injuries in the Plateau State, Nigeria. East Afr Med J 1999; 76: 75-9

115. Hart C, Williams E. Epidemiology of spinal cord injuries: a reflection of changes in South African society. Paraplegia 1994; 32: 709-14.

116. Yeh YS, Lee ST, Lui TN et al. Features of spinal cord injury in Taiwan (1977-1989). Changgeng $Y$ Xue Za Zhi 1993; 16:170-5.

117. Lakhey S, Jha N, Shrestha BP et al. Aetioepidemiological profile of spinal injury patients in Eastern Nepal. Trop Doct 2005; 35: 231 -3.

118. Burke DC, Burley HT, Ungar GH. Data on spinal injuries-Part I. Collection and analysis of 352 consecutive admissions. Aust N Z J Surg 1985; 55: 3-12.

119. Andrews LG, Jung SK. Spinal cord injuries in children in British Columbia. Paraplegia 1979, 17: $442-51$

120. Augutis M, Levi R. Pediatric spinal cord injury in Sweden: incidence, etiology and outcome. Spinal Cord 2003; 41: 328-36.

121. Hamilton MG, Myles ST. Pediatric spinal injury: review of 174 hospital admissions. J Neurosurg 1992; 77: 700-4

122. Nwadinigwe CU, Iloabuchi TC, Nwabude IA. Traumatic spinal cord injuries (SCI): a study of 104 cases. Niger J Med 2004: 13: 161-5.

123. Samsa GP, Patrick CH, Feussner JR. Long-term survival of veterans with traumatic spinal cord injury. Arch Neurol 1993; 50: 909-14.

124. Vitale MG, Goss JM, Matsumoto $\mathrm{H}$ et al. Epidemiology of pediatric spinal cord injury in the United States: years 1997 and 2000. J Pediatr Orthop 2006; $26: 745-9$

125. Zhao YD, Wang W. Neurosurgical trauma in People's Republic of China. World J Surg 2001; 25: $1202-4$

126. Divanoglou A, Westgren N, Seiger A et al. Late mortality during the first year after acute traumatic spinal cord injury: a prospective, populationbased study. J Spinal Cord Med 2010; 33: 117-27.

127. Hartkopp A, Brønnum-Hansen H, Seidenschnur AM et al. Survival and cause of death after traumatic spinal cord injury. A long-term epidemiological survey from Denmark. Spinal Cord 1997; 35: $76-85$

128. Ahoniemi E, Pohjolainen T, Kautiainen H. Survival after spinal cord injury in Finland. J Rehabil Med 2011; 43: $481-5$

129. Hagen EM, Lie SA, Rekand T et al. Mortality after traumatic spinal cord injury: 50 years of followup. J Neurol Neurosurg Psychiatry 2010; 81: 368-73.

130. Tchvaloon E, Front L, Gelernter I et al. Survival, neurological recovery and morbidity after spinal cord injuries following road accidents in Israel. Spinal Cord 2008; 46: 145-9.

131. Pagliacci MC, Franceschini M, Di Clemente B et al. A multicentre follow-up of clinical aspects of traumatic spinal cord injury. Spinal Cord 2007, 45: $404-10$.

132. Zeilig G, Dolev M, Weingarden $\mathrm{H}$ et al. Long-term morbidity and mortality after spinal cord injury: 50 years of follow-up. Spinal Cord 2000; 38: 563-6.

133. Kattail D, Furlan JC, Fehlings MG. Epidemiology and clinical outcomes of acute spine trauma an spinal cord injury: experience from a specialized spine trauma center in Canada in comparison with a large national registry. J Trauma 2009; 67: $936-43$. 
134. Price DL, Manatunga AK. Modelling relative survival using transformation methods. Stat Med 2004; 23: 2463-77

135. Strauss DJ, Devivo MJ, Paculdo DR et al. Trends in life expectancy after spinal cord injury. Arch Phys Med Rehabil 2006; 87: 1079-85.

136. Bohlman HH. Acute fractures and dislocations of the cervical spine. An analysis of three hundred hospitalized patients and review of the literature. J Bone Joint Surg Am 1979; 61: 1119-42.

137. Shavelle RM, DeVivo MJ, Strauss DJ et al. Longterm survival of persons ventilator dependent after spinal cord injury. J Spinal Cord Med 2006; 29: $511-9$.

138. Krause JS, Carter RE, Pickelsimer E. Behavioral risk factors of mortality after spinal cord injury. Arch Phys Med Rehabil 2009; 90: 95-101.

139. Krause JS, Carter RE. Risk of mortality after spinal cord injury: relationship with social support, education, and income. Spinal Cord 2009; 47: $592-6$

140. Krause JS, Carter RE, Pickelsimer EE et al. A prospective study of health and risk of mortality after spinal cord injury. Arch Phys Med Rehabil 2008; 89: 1482-91.

141. Kraus JF, Greenland S. Survival from spinal cord injury. J Chronic Dis 1983; 36: 297-8.

142. Brasil AV, Coelho DG. The neurological outcome of acute spinal cord injury in a neurosurgical hos pital of a developing country. Spinal Cord 1998; 36: 353-6.

143. Neumann CR, Brasil AV, Albers F. Risk factors for mortality in traumatic cervical spinal cord injury: Brazilian data. J Trauma 2009; 67: 67-70.

144. Nwankwo OE, Katchy AU. Outcome of a 12-week programme for management of the spinal cord injured with participation of patient's relations at Hilltop Orthopaedic Hospital, Enugu, Nigeria. Spinal Cord 2003; 41: 129-33.

145. Nwuga VC. A follow-up study of paraplegics and tetraplegics discharged from hospital. J Trop Med Hyg 1979; 82: 30-3.

146. O'Connor PJ. Survival after spinal cord injury in Australia. Arch Phys Med Rehabil 2005; 86 $37-47$

147. Hagen EM, Eide GE, Rekand T et al. Traumatic spinal cord injury and concomitant brain injury: a cohort study. Acta Neurol Scand Suppl 2010; 122: $51-7$.

148. Pagliacci MC, Celani MG, Spizzichino L et al. Spinal cord lesion management in Italy: a 2-year survey. Spinal Cord 2003; 41: 620-8.

149. Pagliacci MC, Celani MG, Spizzichino L et al. Hospital care of postacute spinal cord lesion patients in Italy: analysis of readmissions into the GISEM study. Am J Phys Med Rehabil 2008; 87: 619-26.

150. Werhagen L, Budh CN, Hultling $C$ et al. Neuropathic pain after traumatic spinal cord injury-relations to gender, spinal level, completeness, and age at the time of injury. Spinal Cord 2004; 42: 665-73.

151. Biering-Sørensen M, Biering-Sørensen F. Tracheostomy in spinal cord injured: frequency and follow up. Paraplegia 1992; 30: 656-60.

152. Geisler WO, Jousse AT, Wynne-Jones M et al.
Survival in traumatic spinal cord injury. Paraplegia $1983 ; 21: 364-73$

153. Hartkopp PA, Brønnum-Hansen H, Seidenschnur $A M$ et al. Overlevelse og dødsårsager efter traumatisk rygmarvsskade. En epidemiologisk langtidsstudie. Ugeskr Læger 1998; 160: 6207-10.

154. Price M. Causes of death in 11 of 227 patients with traumatic spinal cord injury over period of nine years. Paraplegia 1973; 11: 217-20.

155. Le CT. Price M. Survival from spinal cord injury. J Chronic Dis 1982; 35: 487-92.

156. Ravichandran G, Silver JR. Survival following traumatic tetraplegia. Paraplegia 1982; 20 : 264-9.

157. Soden RJ, Walsh J, Middleton JW et al. Causes of death after spinal cord injury. Spinal Cord 2000; 38: 604-10.

158. van den Berg ME, Castellote JM, de PedroCuesta J et al. Survival after spinal cord injury: a systematic review. J Neurotrauma 2010; 27: 1517-28.

159. Cripps RA, Lee BB, Wing P et al. A global map for traumatic spinal cord injury epidemiology: towards a living data repository for injury prevention. Spinal Cord 2011; 49: 493-501.

160. Wyndaele M, Wyndaele JJ. Incidence, prevalence and epidemiology of spinal cord injury: what learns a worldwide literature survey? Spinal Cord 2006; 44: 523-9

161. van den Berg ME, Castellote JM, Mahillo-Fernandez I et al. Incidence of spinal cord injury worldwide: a systematic review. Neuroepidemiology 2010; 34: 184-92.

162. Chiu WT, Lin HC, Lam C et al. Review paper: epidemiology of traumatic spinal cord injury: comparisons between developed and developing countries. Asia Pac J Public Health 2010; 22: 9-18.

163. Ackery A, Tator C, Krassioukov A. A global perspective on spinal cord injury epidemiology. J Neurotrauma 2004: 21: 1355-70.

164. Hagen EM, Rekand T, Gilhus NE et al. Diagnostic coding accuracy for traumatic spinal cord injuries. Spinal Cord 2009; 47: 367-71.

165. DeVivo MJ, Chen Y. Trends in new injuries, prevalent cases, and aging with spinal cord injury. Arch Phys Med Rehabil 2011; 92: 332-8.

166. DeVivo M, Biering-Sørensen F, Charlifue $S$ et al. International Spinal Cord Injury Core Data Set. Spinal Cord 2006; 44: 535-40.

167. Blitvich JD, McElroy GK, Blanksby BA et al. Characteristics of «low risk» and «high risk» dives by young adults: risk reduction in spinal cord injury. Spinal Cord 1999; 37: 553-9.

168. Rekand T, Schaanning EE, Varga $V$ et al. Spinal cord injuries among paragliders in Norway. Spinal Cord 2008; 46: 412-6.

169. Ditunno JF jr., Young W, Donovan WH et al. The international standards booklet for neurological and functional classification of spinal cord injury. Paraplegia 1994; 32: 70-80

170. Rowland JW, Hawryluk GW, Kwon B et al. Current status of acute spinal cord injury pathophysiology and emerging therapies: promise on the horizon. Neurosurg Focus 2008; 25: E2.
171. Hjeltnes N. Ryggmargsskade. I: Bahr R, red. Aktivitetshåndboken - fysisk aktivitet i forebygging og behandling. Rapport IS-1592. utg. Oslo: Helsedirektoratet, 2009: 523-36.

172. DeVivo MJ Krause JS, Lammertse DP. Recent trends in mortality and causes of death among persons with spinal cord injury. Arch Phys Med Rehabil 1999; 80: 1411-9.

173. Frankel HL, Coll JR, Charlifue SW et al. Longterm survival in spinal cord injury: a fifty year investigation. Spinal Cord 1998; 36: 266-74.

174. Garshick E, Kelley A, Cohen SA et al. A prospective assessment of mortality in chronic spinal cord injury. Spinal Cord 2005; 43: 408-16.

175. Saunders LL, Selassie AW, Hill EG et al. Traumatic spinal cord injury mortality, 1981-1998. J Trauma 2009; 66: 184-90.

176. Skaga NO, Eken T, Jones JM et al. Different definitions of patient outcome: consequences for performance analysis in trauma. Injury 2008; 39: $612-22$.

177. Nasjonalt folkehelseinstitutt. Kodebok dødsårsaksregisteret 1951-2004 Gjennomgående ICDkoding (ICD6/7-10) for europeisk kortliste. Oslo: Nasjonalt folkehelseinstitutt; 2007.

178. Hartkopp A, Brønnum-Hansen H, Seidenschnur AM et al. Suicide in a spinal cord injured population: its relation to functional status. Arch Phys Med Rehabil 1998; 79: 1356-61.

179. Puisto V, Kääriäinen S, Impinen A et al. Incidence of spinal and spinal cord injuries and their surgical treatment in children and adolescents: a population-based study. Spine 2010; 35: 104-7.

180. Hagen EM, Eide GE, Elgen I. Traumatic spinal cord injury among children and adolescents; a cohort study in western Norway. Spinal Cord 2011; 49: 981-5.

181. DeVivo MJ, Kartus PL, Rutt RD et al. The influence of age at time of spinal cord injury on rehabilitation outcome. Arch Neurol 1990; 47: 687-91.

182. Cifu DX, Seel RT, Kreutzer JS et al. Age, outcome, and rehabilitation costs after tetraplegia spinal cord injury. NeuroRehabilitation 1999; 12: 177-85.

183. Hagen EM, Aarli JA, Gronning M. The clinical significance of spinal cord injuries in patients older than 60 years of age. Acta Neurol Scand 2005; 112: $42-7$

184. Sommer JL, Witkiewicz PM. The therapeutic challenges of dual diagnosis: TBI/SCI. Brain Inj 2004: 18: 1297-308.

185. Macciocchi SN, Bowman B, Coker J et al. Effect of co-morbid traumatic brain injury on functional outcome of persons with spinal cord injuries. Am J Phys Med Rehabil 2004; 83: 22-6.

186. Tolonen A, Turkka J, Salonen 0 et al. Traumatic brain injury is under-diagnosed in patients with spinal cord injury. J Rehabil Med 2007; 39: 622-6.

Mottatt 12.8. 2010, første revisjon innsendt 29.4. 2011, godkjent 22.12. 2011. Medisinsk redaktør Siri Lunde. 